\title{
ECONOMIA SOLIDÁRIA: A REALIDADE DAS QUEBRADEIRAS DE COCO BABAÇU NO INTERIOR DO BRASIL
}

\author{
Eulálio Campelo Filho* \\ Amanda Gadelha Ferreira Rosa* \\ Robert de Medeiros Lopes Júnior ${ }^{* * *}$ \\ Francisco de Tarso Ribeiro Caselli****
}

RESUMO: Dentro da conjuntura capitalista existe um modo de organização do trabalho que transcende a dicotomia patrão x empregado conhecido como Economia Solidária (ES), pautada nos conceitos de justiça, solidariedade e sustentabilidade. A qual conta entre seus modelos de produção, o extrativismo familiar como um dos principais eixos de abrangência deste modelo de desenvolvimento regional. A partir desta temática, este trabalho teve como objetivo avaliar os ganhos oriundos da economia solidária em uma comunidade de quebradeiras de coco babaçu no interior do Brasil. Para isso, foi lançado mão da observação in loco, e de um questionário semiestruturado onde as respostas foram cruzadas para constatação de melhorias (ou não) nas condições de trabalho, sendo estas utilizadas como parâmetro de avaliação neste estudo. Os resultados observados vão ao encontro do que mostra a literatura onde esse modelo auxilia a comunidade a sobrepor as barreiras econômicas e sociais. Os participantes da pesquisa demonstraram boas perspectivas quanto ao futuro da ES, porém foi constatada a importância do apoio dos órgãos governamentais, da sociedade, e da formação de parcerias com empresas e pesquisadores para o desenvolvimento e valorização das atividades. Conclui-se que o empreendimento solidário, além de gerar renda e conhecimento aos seus integrantes, cria um ecossistema de colaboração crucial para o desenvolvimento social e econômico dentro das comunidades na qual são praticados.

PALAVRAS-CHAVE: Babaçu; Economia solidária; Extrativismo.

Doutorado em Engenharia de Negócios pela Universidade de Karlsruhe/Alemanha. Docente Adjunto IIII da Universidade Federal do Piauí (UFP). Coordenador do Mestrado Profissional em Administração Pública PROFIAP/UFPI. Brasil.

** Graduação em Engenharia de Produção pela Universidade Federal do Piauí, Brasil

*** Graduação em andamento em Engenharia de Produção na Universidade Federal do Piauí, UFPI, Brasil

***** Mestrado em Engenharia de Produção pela Universidade Federal da Paraíba. Docente da Universidade Federal do Piauí, Brasil 


\section{SOLIDARITY ECONOMY: BABAÇU COCONUT BREAKERS IN THE BRAZILIAN HINTERLAND}

ABSTRACT: Solidarity Economy is a type of labor organization which exists within the capitalist situation that transcends the employer-employee dichotomy. SE is based on the concepts of justice, solidarity and sustainability. Within the production models, family extractivism is one of the main axes within the regional development model. Current paper evaluates profits from solidary economy in a community of babaçu coconut breakers in the interior of Brazil. Observations in loco and a semi-structured questionnaire were undertaken. Responses were crossed for detection of improvements (or not) in labor conditions. The latter were employed for the study's assessment. Results corroborate conclusions of the literature showing that the model is an aid to the community to overcome economic and social barriers. Participants revealed good perspectives with regard to SE. However, the importance of support by government organs, society and joint-ventures with firms and researchers was enhanced for the development and valorization of activities. Solidary entrepreneurship not merely produces income and knowledge to members but it also establishes an ecosystem of crucial collaboration for social and economic development of the communities in which it is adopted.

KEY WORDS: Babaçu; Solidarity economy; Extractivism.

\section{INTRODUÇÃO}

Atualmente, mesmo a sociedade estando imersa em um ambiente majoritariamente capitalista, existem meios de produção que se valem não da relação patrão (o que detém os meios de produção) e trabalhador (aquele que vende sua força de trabalho), mas sim do cultivo de um ambiente onde todos são proprietários da organização onde trabalham.

Não se trata da substituição do capitalismo pelo seu antagônico (socialismo), porém uma adaptação de um sistema a outro onde os envolvidos no processo produtivo ganham poder e força de modo igualitário à medida que seus negócios se expandem (DOS SANTOS; VIEIRA; BORINELLI, 2013).

Deste modo, surge então o que se convencionou chamar de economia solidária (ES) que, diferentemente da economia capitalista, fundamenta sua organi- 
zação em práticas sociais emancipadoras e democráticas baseadas no tripé justiça, solidariedade e sustentabilidade, definindo-se, dessa forma, como um modelo de organização social e econômico que se materializa através do trabalho associado, abarcando as áreas da autogestão e ambiental, voltando-se à produção, ao consumo e à comercialização de bens e/ou serviços (ADAMS, 2011).

Neste contexto estão inseridas as cooperativas e associações cujos meios de produção pertencem ao coletivo e sua administração é partilhada entre seus integrantes. A exemplo do exposto pode-se mencionar as associações que vivem do extrativismo do babaçu localizado nos rincões do Brasil.

Assim, procurou-se abordar essa temática no tocante a uma comunidade de quebradeiras de coco babaçu situada na cidade de Esperantina, Piauí, onde objetivou-se avaliar a real eficiência desse modelo de organização quanto à melhoria das condições sociais e econômicas supostamente propiciadas por ele, dado que, de acordo com Lima, Araújo e Rodrigues (2011), a economia solidária tem importante papel no combate à marginalização social dentro das comunidades onde é adotada.

\subsection{APORTE TEÓRICO}

Essa seção se encarrega de descrever no primeiro momento o conceito da economia solidária, e seu histórico, bem como aspectos característicos desse tipo de organização de trabalho no Brasil.

\subsubsection{Economia solidária}

Com origem na disparidade social, a economia solidária teve seus conceitos emergidos no Oeste europeu no início do Século XX. Tendo seu desenvolvimento ocorrido durante o período de industrialização na Europa, e seus conceitos relegados ao terceiro setor no período pós-guerra (LAVILLE, 1994 apud SAHAKIAN; DUNAND, 2015).

No Brasil, a economia solidária tem seu surgimento associado aos altos índices de desemprego e exclusão social. Segundo Luizão (2010), as primeiras experiências desse tipo de organização de trabalho ocorreram na década de 1980 como 
uma resposta ao ambiente social vigente àquela época. Para Lima et al. (2011), esse conceito assumiu visibilidade na década de 1990 com os efeitos da abertura e internacionalização da economia brasileira, dos processos de reconversão industrial e das políticas de cunho liberal da desoneração do Estado. Silva (2011) afirma ainda que a economia solidária avançou nas décadas de 1980 e 1990 como uma reação dos trabalhadores à exclusão social e exploração do trabalho, apresentando-se como uma alternativa ao neoliberalismo que discursava a favor do empreendedorismo individual.

Compreende-se, portanto, que a economia solidária é de importância ao estímulo do desenvolvimento social e econômico, pois surge como um caminho de ação transformadora, de luta por mudanças sociais e desenvolvimento alternativo por meio da preocupação pelo desenvolvimento econômico-social (RAZETO, 1999).

Desta forma, a economia solidária mostra-se maleável, podendo se organizar de diferentes formas (cooperativas, associações, redes de cooperação, entre outras), possuindo a finalidade de produzir bens e/ou serviços a determinado público de maneira sustentável nas esferas social, econômica e ambiental. Prova desta sustentabilidade é o fato que cerca de $72 \%$ dos empreendimentos solidários no Brasil conseguem fechar o ano sem nenhuma dívida e com capacidade para gerar superávits para seus associados (GAIGER, 2008). Contrapondo os dados relacionados aos resultados das empresas privadas, que de acordo com o Serviço Brasileiro de Apoio às Micro e Pequenas Empresas [SEBRAE] (2013), 24,4\% destas organizações fecham suas portas antes de completar dois anos de atividade.

Por outro lado, o desenvolvimento das atividades econômicas no Brasil caracteriza-se pela desigualdade regional. E uma vez que pessoas, empregos e riquezas estão concentrados em núcleos urbanos, existem conflitos de interesses entre as regiôes à medida que tende a reproduzir apenas os interesses das áreas mais influentes da nação (ARAÚJO, 2007; DUNFORD, 2007).

Com isso, surgiram novos meios de produção que buscam minimizar a situação na qual as classes menos favorecidas coexistem. Estas novas alternativas, dentre as quais a economia solidária se encontra, objetivam oferecer oportunidade de inserção do indivíduo no mercado de trabalho a partir da iniciativa própria (CUNHA; SILVA; BORGES, 2011), representada de diversas formas, sendo as principais as que 
seguem o Grupo de Pesquisa em Economia Solidária (ECOSOL) (2013):

Associações: entidades que contam com um expressivo número de pessoas e não tem por finalidade os lucros. Conforme Chanial e Laville (2009), a associação trata-se da tradução em atos do princípio de solidariedade que se expressa pela referência de um bem comum. Em termos legais, as associações são amparadas pelo Código Civil nos artigos 53 a 61 .

Cooperativas de trabalho: as cooperativas são organizações em que todas as etapas de produção são coordenadas pelos próprios trabalhadores e a entrada do integrante dá-se de forma voluntária, sendo, portanto, uma empresa onde todos são sócios e tomam decisões, do mesmo modo como se processam o trabalho, estando relacionados tanto à prestação de serviços quanto ao modelo de uma fábrica (LIMA et al., 2009).

Embora os conceitos de associação e cooperativa possam se misturar, os termos diferem-se principalmente devido à natureza dos processos. Enquanto a associação tem seu foco na promoção da atividade social, a cooperativa procura desenvolver atividades que proporcionam o desenvolvimento de um negócio, a exemplo disso tem-se as cooperativas dedicadas à produção de bens, à prestação de serviços, à comercialização e ao crédito (GAIGER, 2013).

Dada a importância da economia solidária e seu papel na sociedade, foi criada a SENAES (Secretaria Nacional de Economia Solidária), que é o órgão regulamentador dos empreendimentos solidários no Brasil que, segundo o Ministério do Trabalho e Emprego (MTE), teve sua criação com a publicação da Lei $n^{\circ} 10.683$, de 28 de maio de 2003 , e foi instituída com base no Decreto $n^{0} 4.764$, de 24 de junho de 2003.

Assim, compreende-se que a SENAES não só formaliza e regula os empreendimentos solidários como também dá suporte para que estes possam crescer e gerar valor, uma vez que esta secretaria visa a proposição de medidas desenvolvimentistas e a divulgação da economia solidária no Brasil, fortalecendo esse movimento que carrega em seu escopo o lema desenvolvimento por meio da ação coletiva.

A economia solidária não só envolve diferentes formas de organização como também diferentes categorias sociais; Gaiger (2013) aponta, por exemplo, associações de produtores e consumidores, sistemas locais de troca, comunidades nativas e cooperativas dedicadas à produção de bens, à prestação de serviços, à comerciali- 
zação e ao crédito. De acordo com um levantamento do Instituto de Pesquisas Econômicas Aplicadas (IPEA), no Brasil é mostrada a quantidade de empreendimentos por Estado.

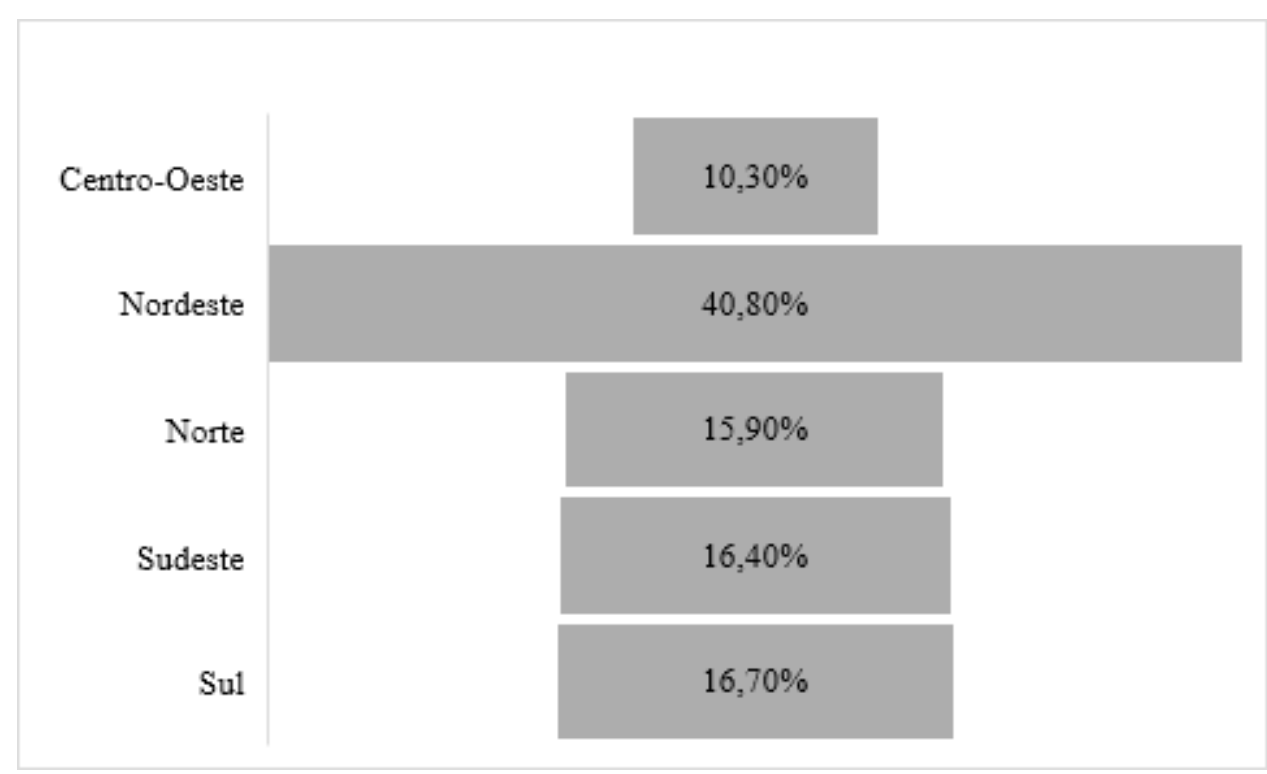

Figura 1. Representação da quantidade de empreendimentos solidários até 2013 Fonte: construído a partir dos dados de IPEA (2016).

Por intermédio da curva de Pareto, percebe-se que a representatividade da região Nordeste corresponde a 40,8\% do total registrado no Brasil, seguido das regiões Sudeste, Sul, Norte e Centro-Oeste. O IPEA (2016) aponta que as causas de surgimento são as mais diversas onde 46,2\% afirmam que uma alternativa para o desemprego enquanto 43,1\% dizem aumentar seus ganhos, 48,8\% complementação da renda e 9,6 \% outros motivos. Importante destacar que aumentar os ganhos difere de complementar a renda, uma vez que o primeiro visa maximização de lucros e o segundo está relacionado à complementação para melhorar a qualidade de vida. 


\subsubsection{A cultura do Coco Babaçu}

Devido seu papel importante como fonte de complementação de renda e alternativa àqueles desempregados, o extrativismo está fortemente associado à dualidade entre o desenvolvimento econômico versus a conservação dos recursos naturais, mostrando intensa correlação com a questão social e econômica. Próxima à economia solidária, a extração vegetal abrange os produtos borracha, gomas não elásticas, fibras, tanantes, oleaginosas, alimentícios, aromáticos, medicinais, tóxicos e corante, madeiras e pinheiro brasileiro (IBGE, 2014).

Dentre os produtos classificados como de extração, as oleaginosas possuem destaque devido à sua grande utilidade para a geração de energia, valor nutricional, utilização na fabricação de fármacos, estudo para aplicação em combustíveis, entre outros, a exemplo do coco babaçu.

As atividades de coleta e quebra do babaçu, organizadas por associações e cooperativas, também se incluem como empreendimentos solidários que buscam diminuir as dificuldades sociais e econômicas de seus integrantes.

O babaçu sobressai em meio a oleaginosas como o pequi, tucum e a copaíba por ter um alto volume de produção. Apesar de sua área de distribuição estar bastante dispersa no território brasileiro, os babaçuais são predominantes na região dos Estados do Maranhão, Piauí e Tocantins, correspondendo a uma área de mais de 25 milhões de hectares, conforme a Figura 3 (MIQCB, 2015). 


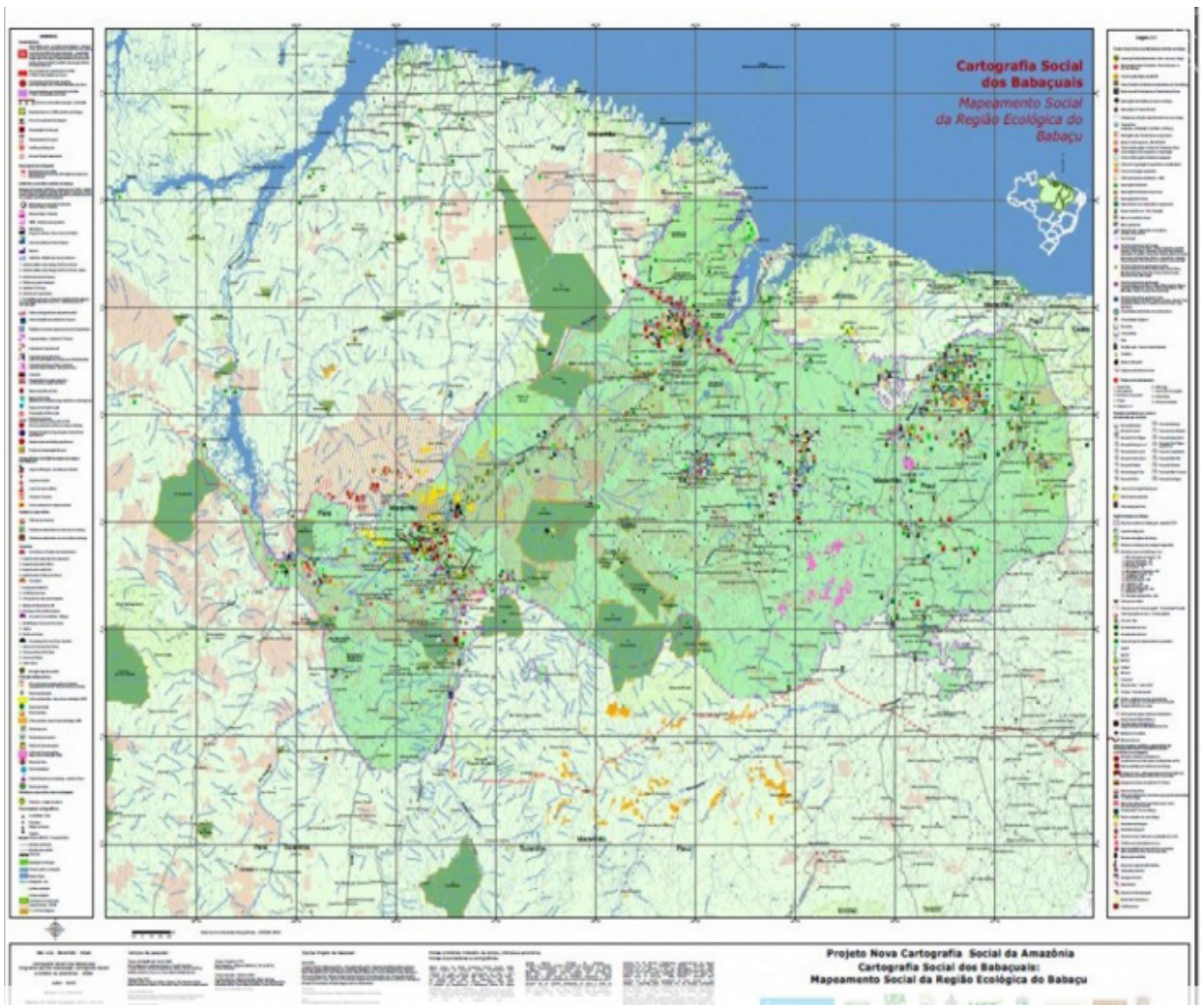

Figura 3. Área de abrangência do coco Babaçu

Fonte: MIQCB (2015). Disponível em: < https://www.socioambiental.org/pt-br/noticias-socioambientais/mapa-revela-aumento-da-incidencia-de-babacuais-no-pi-to-ma-e-pa >

Quando da análise da cadeia de produção do babaçu, tem-se que os processos são relativamente simples e consistem basicamente da extração dos cachos com cocos na floresta e em seguida é realizado o processamento, onde ocorre a separação da amêndoa da casca do coco para posterior produção de óleo de babaçu, além da geração de coprodutos como artesanato, carvão, farinha, etanol, entre outros.

Além de grande potencial de utilização, o coco babaçu vem ganhando destaque devido à questão da sustentabilidade, por ser um produto natural ele vem sendo visto com bons olhos para substituição de combustíveis fósseis. Um exemplo clássico é o estudo do óleo de babaçu na indústria automotiva, sendo este adotado para a produção de biocombustíveis, outra utilização do babaçu no ramo de com- 
bustível está na sua capacidade calorífica, sendo possível a fabricação de briquetes em substituição aos combustíveis fósseis como o carvão para aquecimento de caldeiras em processos industriais. Ademais, outro grande interesse no babaçu está em suas aplicações na indústria de cosméticos e farmácia (SOUZA et al., 2011; ROUSSET et al., 2013; FERRARI; SOLER, 2015).

O fluxo da cadeia produtiva do babaçu é caracterizado em etapas. A primeira consiste na coleta do coco pelas quebradeiras, após os cocos coletados são transportados até o local onde as amêndoas serão separadas do mesocarpo. Em seguida, os cocos são postos para secar para a retirada da umidade do fruto. Os cocos secos, por sua vez, são selecionados para a quebra e posterior separação do endocarpo da amêndoa. Do endocarpo faz-se o carvão, enquanto que a amêndoa fornece o óleo (também chamado de azeite) e a torta (farelo, ração para os animais).

Por mais simples que o processo produtivo do coco babaçu possa parecer, as condições de trabalho das quebradeiras nem sempre são vantajosas, pois elas estão sujeitas aos proprietários da terra (PUTTI; LUDWING; RAVAZI, 2012).

Devido às precariedades das condições de trabalho, as quebradeiras, em âmbito local, se organizaram em associações e cooperativas como meio de ganhar representatividade e firmar a existência do grupo quanto entidade de importância à economia local. No entanto, a fim de fortalecer o movimento de reconhecimento e valorização dessa atividade, diferentes associações e cooperativas de diferentes Estados se uniram no que se definiu no Movimento Interestadual das Quebradeiras de Coco Babaçu.

O movimento surgiu do agrupamento organizado das quebradeiras na metade da década de 1980, devido às tensões e conflitos pelo acesso às áreas de babaçuais por essas mulheres, vindo a se consolidar em 1991 com o primeiro Encontro Interestadual das Quebradeiras de Coco Babaçu na cidade de São Luís, Maranhão, que mais tarde veio a ser batizado MIQCB Departamento de Estudos Sócio Econômicos (DESER) (2007).

O movimento tem a missão de "organizar quebradeiras de coco babaçu para conhecerem seus direitos, defenderem as palmeiras de babaçu, o meio ambiente e a melhoria das condições de vida nas regiões de extrativismo de babaçu", e está organizado em seis regionais, sendo as regionais Baixada Maranhense, Tocantins e 
Médio Mearim localizadas no Estado do Maranhão, Bico de Papagaio no Estado do Tocantins, Araguaia no Estado do Pará e Cocais no Estado do Piauí (MIQCB, 2015).

Dentre as vantagens que o MIQCB fornece aos seus associados pode-se mencionar o apoio e aprendizado de técnicas e conhecimentos relacionados ao plantio e cultivo, bem como acesso aos benefícios financeiros de órgãos do governo e acesso às terras. No entanto este último também se apresenta como ponto crítico, uma vez que existem barreiras ao acesso aos babaçuais, tendo em vista as dificuldades e burocracias que os associados enfrentam ao reivindicarem o direito às áreas no INCRA, que se abstém dos problemas agrários (BOLONHÊS; OLIVEIRAS; ABREU, 2013).

\section{METODOLOGIA DO TRABALHO}

O presente trabalho se propôs em realizar uma análise da real situação dos empreendimentos solidários no Brasil, tendo por base as organizações de quebradeiras de coco babaçu ligadas ao MIQCB. Assim, o projeto constitui-se em um estudo de caso onde, além de buscas bibliográficas referentes à economia solidária, foram realizadas visitas técnicas a uma comunidade de quebradeiras de coco babaçu visando o entendimento da dinamicidade do trabalho e o aprofundamento da temática abordada.

Para isso, aplicou-se um questionário junto a uma comunidade de quebradeiras de coco babaçu associada ao MIQCB. A comunidade em questão foi o povoado Fortaleza, situado no município de Esperantina (PI). Outro questionário também foi aplicado junto à coordenadora da comunidade com o propósito de traçar um paralelo entre as percepções que as diferentes partes têm acerca do empreendimento solidário pesquisado.

O questionário destinado ao pessoal de quebra e coleta do babaçu foi dividido em seis seções: identificação do respondente, organização da coleta do babaçu, processo de coleta do babaçu, beneficiamento do coco, comercialização e considerações. Não obstante, para se validar o questionário foi realizado um pré-teste do questionário no mês de junho de 2016 junto à representante e algumas coordenadoras da regional de Cocais, no escritório da MIQCB na cidade de Esperantina (PI). Após 
a validação do instrumento de coleta de dados, os questionários foram aplicados junto às quebradeiras de coco babaçu e à coordenadora da comunidade Fortaleza no mês de julho de 2016.

Quanto à seleção da amostra, Kauark, Manhães e Medeiros (2010) apresentam esse conceito como sendo o subconjunto da população que é tomada como objeto de estudo da pesquisa. Para a aplicação do questionário, utilizou-se uma amostragem por conveniência, haja visto que a comunidade estudada foi escolhida segundo o critério de facilidade de acesso, sendo então realizado um censo dos integrantes vinculados ao MIQCB da localidade em questão. Ochoa (2015) recorda que essa amostragem é empregada quando não se possui acesso à lista completa de indivíduos que formam a população, como é o caso da pesquisa levantada.

A aplicação do questionário direcionado às quebradeiras foi realizada individualmente com cada uma durante a visita ocorrida na cooperativa no ambiente de trabalho delas. Mediante a aplicação do questionário ao grupo de quebradeiras, os dados levantados foram tabulados no software Microsoft Excelß. Após, realizou-se uma análise das respostas e comparação com o questionário respondido pela coordenadora da comunidade, utilizando-se para tanto a estatística descritiva e a análise de conteúdo como estratégia de tratamento dos dados e a conceituação de Bardin acerca dessa técnica como parâmetro para sua utilização. Segundo ele, a análise de conteúdo é "um conjunto de técnicas de análise das comunicações que utiliza procedimentos sistemáticos e objetivos de descrição do conteúdo das mensagens" (BARDIN apud GRZYBOVSKI, 2011, p. 734).

\section{RESULTADOS}

A partir da aplicação do questionário junto à coordenadora e aos integrantes da comunidade Fortaleza, localizada na cidade de Esperantina (PI), algumas informações puderam ser obtidas.

Inicialmente averiguou-se que parte da amostra levantada não possui uma ideia clara do que seria associação e cooperativa. Fato justificado na apropriação da ideia de coletivo que ambos os termos partilham. 
No entanto, em conversa informal com a representante e algumas coordenadoras da regional Cocais, ficou claro que a comercialização dos produtos manufaturados pelas quebradeiras ocorre por intermédio da cooperativa, uma vez que a associação está restrita à organização das pessoas. Assim, percebe-se uma ausência de comunicação entre as pessoas que estão na coordenação e as demais quebradeiras.

O levantamento realizado na comunidade demonstrou características intrínsecas ao grupo quanto à idade, sexo e escolaridade. A partir dos levantamentos realizados o estudo apontou a presença majoritária do grupo de indivíduos com idade entre 22 a 32 anos, e entre 52 e 62 anos, onde cada um dos grupos teve representatividade de aproximadamente 33,33\%.

Responsáveis por $83,33 \%$ do trabalho, as mulheres se apresentaram como as maiores responsáveis pelo processo produtivo da cadeia do babaçu. Fato esse que corrobora com os estudos feitos por Costa (2011), que apresenta a expressiva presença feminina em grupos que se articulam em movimentos sociais, bem como em grupos mais frágeis e precários.

Outro aspecto analisado foi o grau de escolaridade dos integrantes da associação pertencentes à comunidade, onde notou-se que metade dos associados possuíam ensino fundamental incompleto, enquanto 33,33\% não possuem escolaridade, ratificando o ponto de vista dos autores apresentados no aporte teórico que afirmam que a economia solidária é empregada como um meio alternativo de geração de renda e conhecimento para pessoas menos favorecidas economicamente.

Não obstante, alguns aspectos relativos à produção também puderam ser levantados. Um dos pontos observados foi a existência de um planejamento da atividade de coleta e quebra do babaçu antes e depois da formação da associação.

Dentre os entrevistados $41,67 \%$ disseram desconherer qualquer tipo de organização da atividade de coleta de babaçu antes de se associarem ao MIQCB. Porém, notou-se que embora 58,33\% dos entrevistados tenham relatado a existência de planejamento (que ocorre por meio de reuniões entre os associados) para a atividade de coleta e quebra antes da associação, quando comparado com o período pós associação esse percentual sobe em 33,34. No entanto, apesar de a maioria dos integrantes apontarem a existência do planejamento nas atividades, existe ainda um pequeno percentual de $8,33 \%$ que indica a inexistência do planejamento. 
Em análise realizada aos questionários respondidos pelas mulheres diretamente ligadas à quebra do babaçu, constatou-se que 75\% dos entrevistados participam da coleta do fruto, e que o tempo gasto com essa atividade atingia duração média de 3,5 horas diárias de trabalho.

Em contrapartida, o tempo empenhado na quebra do babaçu possui duração média de 5,75 horas. Além disso, segundo 91,67\% dos entrevistados, essa atividade ocorre no espaço físico da associação presente na comunidade.

Os processos de coleta e quebra são marcados por métodos arcaicos e manuais, de acordo com as entrevistas e a observação dos pesquisadores durante as visitas. Na coleta, os equipamentos utilizados são: facão, cofo (saco feito da trança da palha do babaçu), saco e vara. O facão e a vara são instrumentos utilizados para a derrubada dos cocos, enquanto que o saco e o cofo são utilizados no transporte dos cocos coletados.

Já a quebra do babaçu se processa por meio da utilização de dois instrumentos: machado e macete (madeira maciça e pesada). Nessa atividade o indivíduo apoia o coco sobre a lâmina cortante do machado e o acerta com o macete para quebrá-lo, com a finalidade de retirar suas amêndoas. Assim, as amêndoas boas são separadas em um recipiente, enquanto as amêndoas ruins são inutilizadas e a casca do coco é separada em outro recipiente.

Ainda em relação à quebra e coleta do babaçu, boa parte dos entrevistados afirmaram estar expostos a riscos com animais peçonhentos no mato, afora a existência das dificuldades de acesso aos babaçuais, principalmente nos períodos de maio a novembro quando as chuvas são escassas e o período não é favorável ao babaçu. Também são relatadas dificuldades enfrentadas no estabelecimento de um preço de venda justo dos produtos produzidos.

No tocante aos produtos produzidos, o questionário aplicado aponta que a farinha do mesocarpo e o óleo do babaçu são os que apresentam maior retorno financeiro, com representatividade de $41,67 \%$ cada um desses produtos, conforme retratado na Figura 4. 


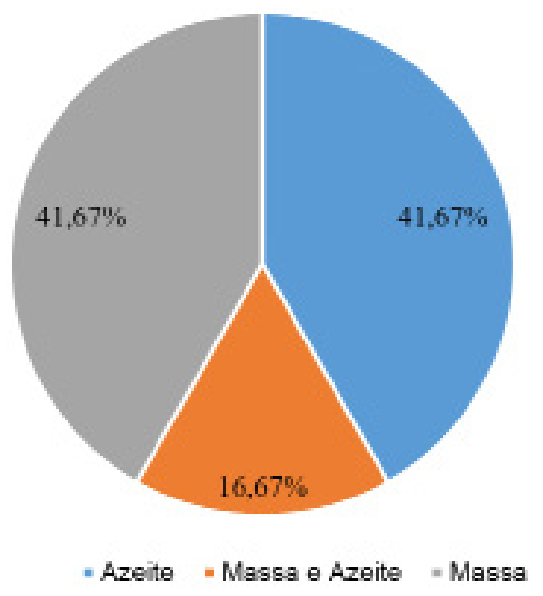

Figura 4. Produto com maior retorno Fonte: Elaborado pelo autor.

Neste quesito, percebe-se uma ponderação entre os entrevistados, uma vez que foi relatado que embora a massa seja produzida em menor quantidade seu preço de venda é compensatório. Por outro lado, outro grupo de entrevistados apontou que azeite (óleo) do babaçu é mais rentável tendo em vista que este é produzido em maior quantidade que a massa e, portanto, os lucros obtidos com esse produto seriam maiores. Houve ainda um terceiro grupo que considerou tanto a massa do mesocarpo quanto o azeite os produtos de maior retorno financeiro.

Quanto à dificuldade de obtenção de um produto, de acordo com 41,67\% dos entrevistados, o produto mais trabalhoso de ser feito é a farinha do mesocarpo, pois seu processo consiste nas etapas de caça, limpeza e lavagem do coco seguido dos processos de retirada da casca e massa, secagem, moagem, passagem no pano "volta ao mundo" (pano utilizado para a retirada da umidade da massa) e embalagem.

No que tange a atividade de comercialização, a análise dos questionários apontou que esta ocorre principalmente por intermédio de cooperativa $(91,62 \%$ dos entrevistados) e feirantes (100\% dos entrevistados), neste último os próprios associados fazem a venda de seus produtos nas feiras.

Quando se realiza uma análise do impacto que o empreendimento solidário tem na vida dessas pessoas, 83,34\% afirmam que a cooperativa tem importân- 
cia crucial no papel de apoio à comercialização, tendo em vista que esta dá maior credibilidade aos produtos, favorece maior volume de vendas, além dos benefícios conseguidos com os programas do governo do Estado e prefeitura municipal.

O resultado obtido pelo questionário direcionado à coordenadora da comunidade foi mais voltado aos processos de coleta, quebra e comercialização, e seus extratos vão de encontro aos dados e informações levantadas na comunidade, mostrando uma sintonia e convergência de interesses entre os associados, independente do grau hierárquico presente nesse tipo de organização.

Em consonância com a literatura sobre economia solidária, apresentada no aporte teórico, o empreendimento solidário estudado mostra-se, de fato, eficaz em ofertar trabalho e renda às pessoas marginalizadas não só economicamente como socialmente, no entanto ainda existem barreiras a serem ultrapassadas, conforme observado em visita feita à comunidade ligada ao MIQCB.

Dentre as dificuldades, foram relatadas as dificuldades de acesso às terras de babaçuais, assim como dificuldades de manutenção e aprimoramento do beneficiamento da produção, uma vez que o local utilizado atualmente para este fim se trata de um espaço cedido, sem nenhuma garantia contratual.

\section{CONCLUSÕES}

O estudo realizado teve por objetivo avaliar a dinâmica organizacional de um empreendimento solidário a partir da análise das percepções que os indivíduos de uma comunidade de quebradeiras vinculada ao MIQCB têm sobre o empreendimento no que tange a organização do trabalho e seus benefícios econômicos e sociais. Para isso aplicou-se dois questionários, um direcionado ao pessoal de quebra e coleta do coco babaçu e outro à coordenadora da comunidade a fim de se avaliar a convergência dos interesses dos envolvidos no processo.

A partir da análise dos dados levantados, pode-se perceber que o trabalho realizado vai ao encontro do que é apresentado pela literatura de economia solidária, sendo perceptível o uso desse modelo de organização como uma maneira de sobrepor as barreiras econômicas e sociais da comunidade estudada. 
No estudo em questão ficou claro que apesar das dificuldades enfrentadas por esse grupo, a união dos indivíduos que buscam interesses em comum fortalece a causa e chama a atenção aos setores menos abastados. Na comunidade Fortaleza, por exemplo, percebeu-se a presença de equipamento e espaços adquiridos através da organização para a produção dos produtos derivados do babaçu, além disso é perceptível o conhecimento de questões agrárias e direitos, ficando claro que os integrantes passam a reconhecer e exigir melhores condições de vida, mais escolas, mais saúde e mais direitos, a partir do seu envolvimento com as atividades da economia solidária.

No entanto, apesar dos entrevistados possuírem boas perspectivas quanto a este modelo de gestão social, estes acreditam que o apoio dos órgãos governamentais e sociedade, parcerias com empresas e pesquisadores são decisivos para o maior desenvolvimento e valorização de suas atividades.

Outros pontos identificados como relevantes para futuros estudos buscando o aprimoramento desta atividade e o alcance de maiores retornos econômico-sociais seriam: a questão da saúde e segurança do trabalho das quebradeiras, a ergonomia do processo de coleta e beneficiamento dos cocos, métodos de produção mais adequados e padronizados, o diagnóstico de toda cadeia produtiva envolvida, entre outros.

Deste modo, conclui-se que o empreendimento solidário, além de gerar renda e conhecimento aos seus integrantes, é um campo aberto ao estudo de processos produtivos e desenvolvimento social por apresentar a possibilidade de se implantar melhorias aos processos organizacionais, financeiros e sociais dentro da comunidade onde este modelo é efetivamente implementado.

\section{REFERÊNCIAS}

ADAMS, T.; SCHOLZ, R. H.; DE MELLO CARGNIN, T.; HOSSEIN, T. S. Tecnologia Social e Economia Solidária: desafios educativos. Diálogo, v. 18, p-13, 2011.

ARAÚJO, T. B. D. Brasil: desafios de uma política nacional de desenvolvimento regional contemporânea. In: DINIZ, C. C. Políticas de desenvolvimento regional: desafios e perspectivas à luz das experiências da União Europeia e do Brasil. Brasília: Ed. da UNB, 2007. 
BOLONHÊS, A. C.; OLIVEIRAS, P. S. de; ABREU, K. D. R. de. Relatório de pesquisa - projeto de conexão local: Movimento Interestadual das Quebradeiras de Coco Babaçu (Relatório de Pesquisa/2013). São Paulo: Fundação Getúlio Vargas, 2013.

CANÇADO, A. C. Desenvolvimento, gestão e questão social: uma abordagem interdisciplinar. [s.l.]: Didática, 2011.

CHANIAL, P.; LAVILLE, J.-L. Associativismo. In: A. CATTANI et al. (Org.). Dicionário internacional da outra economia. Coimbra: Almedina, 2009. p. 21-25.

COSTA, J. C. Mulheres e economia solidária: hora de discutir a relação! Sociedade e Cultura, v. 14, n. 1, 10-5216, 2011.

CUNHA, A. M. S.; SILVA, A. C.; BORGES, D. P. Incubação de um empreendimento de economia solidária: o trabalho na ASCAMPA- Associação de Catadores (as) de materiais recicláveis da região centro norte de Palmas - TO. [s.l;;s.n.], 2011.

DESER - Departamento de Estudos Sócio-Econômicos. A cadeia produtiva do babaçu: estudo exploratório. [sl.1]: Secretaria de Agricultura Familiar/MDA, 2007. (Relatório Técnico) (Convênio MDA 112/2006).

DUNFORD, M. Desenvolvimento territorial, bem-estar e crescimento: razões em favor das políticas regionais. In: CAMPOLINA, C. Políticas de desenvolvimento regional: desafios e perspectivas à luz das experiências da União Europeia e do Brasil. [s.1.;s.n], 2007. (n. IICA E11-45).

ECONOMIA SOLIDÁRIA - Ecosol. 2017. Ecosolbasebrasilia.com.br. Disponível em: $<$ http://www.ecosolbasebrasilia.com.br/index.php/economia-solidaria/videos $>$. Acesso em: 21 oct. 2017.

FERRARI, R. A.; SOLER, M. P. Obtention and characterization of coconut babassu derivatives. Scientia Agricola, v. 72, n. 4, p. 291-296, 2015.

GAIGER, L. I. A economia solidária e a revitalização do paradigma cooperativo. Revista Brasileira de Ciências Sociais, v. 28, n. 82, p. 211- 259, 2013.

GAIGER, L. I. G. Brasil: un retrato de la lucha emancipatoria de los pobres. Otra Economía, v. 2, n. 2, p. 17-21, 2011. 
IBGE, Instituto Brasileiro de Geografia e Estatística. 2017. Disponível em: < http:// www.ibge.gov.br/home/estatistica/economia/pevs/2014/default.shtm > . Acesso em: 22 oct. 2016,

IPEA. Os novos dados do mapeamento de economia solidária no Brasil: nota metodológica e análise das dimensões socioestruturais dos empreendimentos. Tradução. Brasília: Governo Federal/IPEA, 2016. Dinponível em: < http://repositorio.ipea.gov. br/bitstream/11058/7410/1/RP_Os\%20Novos\%20dados\%20do\%20mapeamento\%20 de\%20economia\%20solid\%C3\%A1ria\%20no\%20Brasil_2016.pdf $>$. Acesso em: 20 jan. 2017,

KAUARK, F. D. S.; MANHÃES, F. C.; MEDEIROS, C. H. Metodologia da pesquisa: um guia prático. [s.l.;S.n], 2010.

LIMA, J. C.; ARAÚJO, A. M. C.; RODRIGUES, C. C. P. Empreendimentos urbanos de economia solidária: alternativa de emprego ou política de inserção social? Sociologia \& Antropologia, v. 1, n. 2, p. 119, 2011.

LIMA, J. C. Cooperativas de Trabalho. In: CATTANI, A. D.; LAVILLE, J.-L.; GAIGER, L. I.; HESPANHA, P. Dicionário internacional da outra economia. Coimbra: Almedina, 2009.

LUIZÃO, F. M. C.; ANTONELLO, I. T. Economia solidária como política: alternativa à exclusão socioespacial. In: PITAGUARI, S. O.; LANZA, L. M. B.; CORDEIRO, S. M. A. Londrina: Universidade Estadual de Londrina, 2012.

MINISTÉRIO DO TRABALHO E EMPREGO. Conselho nacional da economia solidária. Brasília: TEM, 2017. Disponível em: < http://trabalho.gov.br/trabalhador-economia-solidaria/conselho-nacional-de-economia-solidaria-cnes $>$. Recuperado 20 set. 2017

MIQCB, M. Acesso à terra, território e recursos naturais: a luta das quebradeiras de coco babaçu. [s.l.]: ActionAid Brasil, 2015. Disponível em: < http://www.actionaid. org.br/sites/files/actionaid/quebradeiras_actionaid_port_rev1.pdf $>$. Acesso em: 30 set. 2016.

MOZZATO, A. R.; GRZYBOVSKI, D. 2011. Análise de conteúdo como técnica de análise de dados qualitativos no campo da administração: potencial e desafios. Revista 
de Administração Contemporânea, v. 15, n. 4, p. 731-747, 2011.

OCHOA, C. Amostragem não probabilística: Amostra por conveniência. Netquest. com. 2017. Disponível em: < http://www.netquest.com/blog/br/amostra-conveniencia/> . Recuperado 20 set. 2017,

PUTTI, F. F.; LUDWIG, R.; RAVAZI, A. S. Análise da viabilidade e rentabilidade do uso do babaçu para a produção do biodiesel. Fórum Ambiental da Alta Paulista, v. 8, n. 7, 2012.

RAZETO, L. La economía de solidaridad: concepto, realidad y proyecto. Persona y sociedad, v. 13, n. 2, p. 1-19, 1999.

ROUSSET, P.; AGUIAR, C.; VOLLE, G.; ANACLETO, J.; DE SOUZA, M. Torrefaction of Babassu: A potential utilization pathway. BioResources, v. 8, n. 1, p. 358-370, 2012.

SAHAKIAN, M. D.; DUNAND, C. The social and solidarity economy towards greater 'sustainability': learning across contexts and cultures, from Geneva to Manila. Community Development Journal, v. 50, n. 3, p. 403-417, 2015.

SANTOS, L. M. L.; VIEIRA, S. F. A.; BORINELLI, B. dos. Economia solidária e estratégia: entre princípios e pragmatismo. Revista Ibero-Americana de Estratégia, v. 12, n. 4, p. 261, 2013.

SEBRAE, SERVIÇO BRASILEIRO DE APOIO ÀS MICRO E PEQUENAS EMPRESAS. SObrevivência das empresas no Brasil: coleção estudos e pesquisas. Brasília: SEBRAE, 2013. Disponível em: < https:/www.sebrae.com.br/Sebrae/Portal\%20Sebrae/Anexos/Sobrevivencia_das_empresas_no_Brasil $=2013 . p d f>$.

SILVA, R. M. A. da. Políticas Públicas de Economia Solidária: avanços, desafios e perspectivas. Diálogo, v. 18, p-53, 2011.

SOUZA, M. H.; MONTEIRO, C. A.; FIGUEREDO, P. M.; NASCIMENTO, F. R. F.; GUERRA, R. N. Ethnopharmacological use of babassu (Orbignya phalerata Mart) in communities of babassu nut breakers in Maranhão, Brazil. Journal of ethnopharmacolog y, v. 133, n. 1, p. 1-5, 2011.

Recebido em: 02/06/2017

Aceito em: 24/05/2018 